\title{
Disruption of the sole IdhL gene in Lactobacillus sakei prevents the production of both L- and D-lactate
}

\author{
Christine Malleret, ${ }^{1}$ R. Lauret, ${ }^{1}$ S. Dusko Ehrlich, ${ }^{2}$ \\ Françoise Morel-Deville ${ }^{1}$ and Monique Zagorec ${ }^{1}$
}

Author for correspondence: Monique Zagorec. Tel: +331346522 89. Fax: +33134652105.

e-mail: zagorec@biotec.jouy.inra.fr

Laboratoire de Recherches sur la Viande 1 and

Laboratoire de Génétique Microbienne 2 , Institut National de la Recherche Agronomique, Domaine de Vilvert, F-78352 Jouy en Josas cedex, France

\begin{abstract}
A 7 kb DNA fragment was cloned from Lactobacillus sakei which contains the IdhL gene encoding the L(+)-lactate dehydrogenase (L-LDH). Analysis of the DNA sequence, Northern experiments and primer extension experiments showed that IdhL is transcribed from a single promoter, leading to a monocistronic $1.15 \mathrm{~kb}$ mRNA which yields the L-LDH. A stable mutant was constructed by chromosomal integration of a chloramphenicol cassette into IdhL by a double-crossover event. Both L- and D-lactate were produced by the wild-type strain whereas only residual amounts of both isomers were produced by the mutant. This demonstrates that $L$. sakei possesses an L-LDH producing L-lactate and a lactate racemase able to transform it to D-lactate, but is devoid of D-LDH activity. Moreover the ability to degrade L-lactate present in the medium that was observed with the mutant strain grown aerobically suggests that an L-lactate oxidase activity is also present in L. sakei.
\end{abstract}

Keywords: lactic acid, lactate dehydrogenase, lactate racemase

\section{INTRODUCTION}

Lactobacillus sakei, formerly called L. sake (Trüper \& De Clari, 1997), is a facultative heterofermentative lactic acid bacterium naturally occurring on fresh meat and meat products, and it can also be found in other products of vegetable origin such as sauerkraut, cucumber or olives. It is used in Western Europe for the industrial production of fermented meat products. Its main role in such processes is the production of lactate by fermentation of carbohydrates. The $\mathrm{pH}$ drop caused by the lactic acid contributes to the quality and hygienic safety of the products. $L$. sakei is known, like the closely related species Lactobacillus curvatus, to produce both $\mathrm{L}$ - and D-lactate. It was previously shown by Stetter \& Kandler (1973) that $L$. sakei produces L-lactate during exponential growth. This production results from the conversion of pyruvate to L-lactate by $\mathrm{L}(+)$-lactate dehydrogenase ( $\mathrm{L}-\mathrm{LDH})$. Part of the L-lactate is then consumed and an equivalent amount of D-lactate is

Abbreviations: $\mathrm{FBP}$, fructose 1,6-bisphosphate; $\mathrm{HiCDH}$, hydroxyisocaproate dehydrogenase; $\mathrm{LDH}$, lactate dehydrogenase.

The GenBank accession number for the sequence reported in this paper is AF054624. produced, the L- to D-lactate conversion being catalysed by lactate racemase. Lactate racemase has been partially purified from L. sakei (Hiyama et al., 1968) and its presence was considered as a characteristic trait of the species $L$. sakei and L. curvatus among lactobacilli (Sneath et al., 1986). In several lactic acid bacteria, the D$\mathrm{LDH}$ is responsible for the production of D-lactate and in several species, D-hydroxyisocaproate dehydrogenases (D-HicDH), sharing sequence similarities with D-LDH, have been reported (Bernard et al., 1994; Delcour et al., 1993). A D-mandelate dehydrogenase belonging to the family of $\mathrm{NAD}^{+}$-dependent 2-hydroxyacid dehydrogenases (Delcour et al., 1993) has been purified from L. curvatus (Hummel et al., 1988). These findings raised the question whether the racemase is the only enzyme responsible for the production of D-lactate and the dissimilation of L-lactate by L. sakei. Among Lactobacillus species, some have both a $\mathrm{D}-$ and an $\mathrm{L}-$ $\mathrm{LDH}$, whereas some have LDH and also HicDH. Several genes encoding these enzymes have been cloned and sequenced from certain lactobacilli. For example the genes of L-LDH and D-LDH have been studied in Lactobacillus plantarum (Ferain et al., 1996). In Lactobacillus bulgaricus a D-HicDH was described (Bernard et al., 1994) as well as a D-LDH (Bernard et al., 1991). In Lactobacillus case $i$ the gene encoding a $\mathrm{D}-\mathrm{HicDH}$ was 
described (Lerch et al., 1989). When we started this study, no information was available on the genes encoding such enzymes in $L$. sakei. The $l d b L$ sequence of an $L$. sakei strain was then submitted to databases by van den Berg (accession number U26688) but no further physiological or genetic results were published.

Our aim was to characterize the $l d h L$ gene encoding the L-LDH of $L$. sakei and to construct a mutant deficient in this activity, in order to investigate lactate metabolism. For this purpose a stable mutant was obtained by double-crossover recombination, leading to the insertion of a chloramphenicol-resistance gene into the chromosomal $l d h L$ gene. The production of the $\mathrm{D}-$ and $\mathrm{L}$ - isomers of lactate by the mutant and the parent strain was studied.

\section{METHODS}

Bacterial strains, plasmids and growth conditions. The $l d h L$ gene was cloned from chromosomal DNA of L. sakei strain 207 from our laboratory stock. The highly transformable strain L. sakei 23K (Berthier et al., 1996) was used as recipient for the construction of mutants. The Escherichia coli strains TG1 (Gibson, 1984) and XL1Blue (Stratagene) were used for cloning, subcloning and sequencing experiments. The plasmids used in this study are shown in Fig. 1(b). Cloning and sequencing experiments were performed with pBluescript phagemids (Stratagene) or M13mp19 phage (Boehringer). Chromosomal mutants were constructed by the use of the integrative vector pRV300 (Leloup et al., 1997), a pBluescript derivative carrying the erythromycin-resistance gene of pAM $\beta 1$.

L. sakei strains were grown at $30^{\circ} \mathrm{C}$ in the complex medium MRS (De Man et al., 1960) or in the chemically defined medium MCD (Lauret et al., 1996). E. coli strains were grown on LB medium (Sambrook et al., 1989). For the induction of $l d h L$ placed under the control of the lac promoter, IPTG was added to a final concentration of $1.5 \mathrm{mM}$. Bacteria were grown aerobically by vigorous shaking ( 240 r.p.m.) of the culture flasks, or under microaerophilic conditions by incubating filled flasks without shaking.

Electrotransformation procedures. L. sakei and E. coli strains were transformed by electroporation as described by Berthier et al. (1996) and Dower et al. (1988), respectively. E. coli transformants were selected on LB plates containing ampicillin $\left(100 \mu \mathrm{g} \mathrm{ml}^{-1}\right)$, erythromycin $\left(200 \mu \mathrm{g} \mathrm{ml}^{-1}\right)$ or chloramphenicol $\left(10 \mu \mathrm{g} \mathrm{ml}^{-1}\right)$. L. sakei transformants were isolated on MRS plates containing chloramphenicol $\left(10 \mu \mathrm{g} \mathrm{ml}^{-1}\right)$ or erythromycin $\left(5 \mu \mathrm{g} \mathrm{ml}^{-1}\right)$.

Nucleic acid techniques. Chromosomal DNA and total RNA were prepared from $L$. sakei as described by Anderson \& McKay (1983) and Stentz et al. (1997), respectively. The standard methods described by Sambrook et al. (1989) were used for DNA manipulations. For electrotransformation of $L$. sakei, plasmids were prepared by alkaline lysis followed by caesium chloride gradient centrifugation (Sambrook et al., 1989). DNA and RNA hybridizations were performed by standard techniques, as previously described (Stentz et al., 1997). The transcription start site of $l d h L$ was determined by primer extension analysis on $10 \mu \mathrm{g}$ total RNA as described by Williams \& Mason (1985). The primer used was complementary to the nucleotides located at the $5^{\prime}$ end of $l d h L$, at position $4191-4209$ in the DNA sequence.
PCR conditions. The two degenerate oligonucleotides $] \mathrm{dh} 1 \mathrm{5}^{\prime}$ TA(C,T)GC(A,C,G,T)AC(A,C,G,T)TGGAA(A,G) 3'] and ldh2 [5' CC (A,G)TG(C,T)TC(A,C,G,T)CCCAT $(A, G, T) A T-$ $\left.(A, G) T A 3^{\prime}\right]$ were used as primers for the amplification by PCR on the chromosomal DNA. PCR amplification was performed on $1 \mu \mathrm{g}$ L. sakei 207 total DNA with a GenAmp PCR system 9600 from Perkin Elmer, with the Taq DNA polymerase from Promega, as previously described (Stentz et al., 1997). Formamide $(1 \cdot 25 \%)$ was added to the reaction mixtures when degenerate primers and chromosomal DNA were used and omitted in the subsequent amplification reactions.

DNA sequencing. Subclones were obtained from the initial clones using restriction enzymes or by generating overlapping deletions by the use of an Exonuclease III/Mung Bean nuclease kit (Stratagene). The dideoxy chain-termination method was used on double- or single-stranded DNA with Taq DNA polymerase, according to the Perkin Elmer protocol for cycle sequencing on the GenAmp PCR system 9600. Dye-coupled primers or synthetic primers and dye-coupled dideoxynucleotides (Applied Biosystems) were used in the sequencing reactions. Sequencing reaction mixtures were analysed on an automatic sequencer (Applied Biosystems). The DNA sequence was analysed with programs from the University of Wisconsin Genetics Computer Group software package. The entire sequence has been determined on both strands.

Measurement of organic compounds. One millilitre culture aliquots were taken at intervals and centrifuged to eliminate the bacteria. The supernatants were stored frozen at $-70^{\circ} \mathrm{C}$ until use. The amounts of L-lactate and D-lactate were measured by the appearance of NADH at $340 \mathrm{~nm}$ in the presence of NAD and L-LDH or D-LDH. Acetate was measured by the appearance of $\mathrm{NADH}$ in the presence of NAD, ATP, CoA, acetyl-CoA synthetase, citrate synthase and malate dehydrogenase. Ethanol was measured by the appearance of NADH in the presence of NAD, alcohol dehydrogenase and aldehyde dehydrogenase. Glucose was measured by the appearance of NADPH in the presence of NADP, ATP, hexokinase and glucose-6-phosphate dehydrogenase. For these assays, Boehringer Mannheim kits were used in the conditions described by the manufacturer. The presence of acetoin was detected with $\alpha$-naphthol as described by Barrit (1936). A control was performed by measuring these compounds in non-inoculated medium. The results are the means of at least three assays from independent experiments and are quoted $\pm S E$.

LDH activity determination. E. coli strains were grown in LB medium to mid-exponential phase and then induced for $1 \mathrm{~h}$ by the addition of IPTG. Bacteria were collected, resuspended in $0 \cdot 1 \mathrm{M}$ triethanolamine, $\mathrm{pH} 6 \cdot 5$, and broken with glass beads. The supernatant of these crude extracts was stored frozen until use. L-LDH activity was measured by the appearance of $\mathrm{NADH}$ at $340 \mathrm{~nm}$, in the conditions described by Hillier \& Jago (1982). Since fructose 1,6-bisphosphate (FBP) has no effect on E. coli LDH (Tarmy \& Kaplan, 1965) but activates, with $\mathrm{Mn}^{2+}$, the L-LDH of L. curvatus (Hensel et al., 1977), the reactions were performed in the presence of $1 \mathrm{mM}$ FBP and $10 \mathrm{mM} \mathrm{MnSO}_{4}$. Five to ten micrograms of proteins from crude extracts were used per assay. One unit is the amount of enzyme that catalyses the pyruvate-dependent oxidation of $1 \mu \mathrm{mol} \mathrm{NADH} \min ^{-1}$ at $30^{\circ} \mathrm{C}$. The results are the means of at least three assays from independent experiments and are quoted $\pm \mathrm{SE}$. 


\section{RESULTS AND DISCUSSION}

\section{Cloning of a $7 \mathrm{~kb}$ DNA fragment encompassing the IdhL gene}

The sequences of several bacterial genes encoding LLDHs, including genes of lactic acid bacteria, have been reported. The corresponding proteins have homologous regions. Two conserved regions, YATWK and YIMGEHG, corresponding to amino acids 135-139 and 179-185, respectively, in the $L$. casei $\mathrm{L}-\mathrm{LDH}$ are homologous in all lactic acid bacteria sequences so far examined. The sequence of two degenerate primers, Idh1 and ldh2, was deduced from these regions. Idh1 and Idh2 were used for the amplification by PCR of a $150 \mathrm{bp}$ DNA fragment that was subsequently used in Southern experiments in order to determine the restriction map of the $L$. sakei chromosome in the $l d h L$ region (Fig. 1a). One $4.7 \mathrm{~kb}$ EcoRI fragment and one $5 \mathrm{~kb}$ HindIII fragment were cloned in $E$. coli by colony hybridization screening with the PCR fragment (plasmids pRV201, pRV202, pRV203; see Fig. 1b). Mapping of the $150 \mathrm{bp}$ PCR fragment in the cloned DNA and preliminary sequencing results showed that the $l d b L$ gene was located at one end of the inserts contained in pRV201, pRV202 and pRV203 and that a small part of the $3^{\prime}$ end might be missing in the cloned inserts. A $450 \mathrm{bp}$

(a)

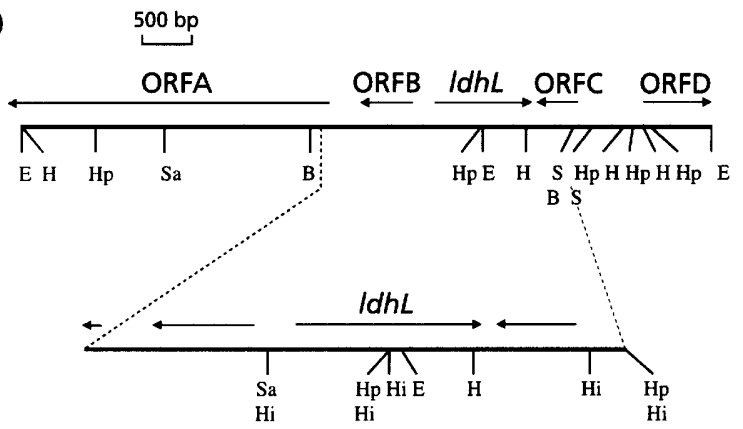

(b)

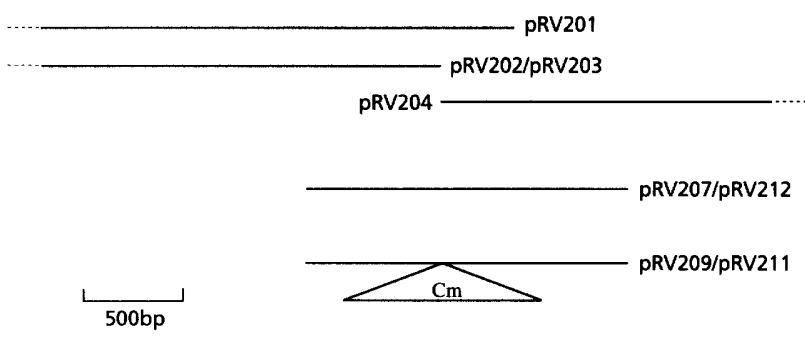

Fig. 1. (a) Restriction map of the $7 \mathrm{~kb}$ DNA region encompassing the $L$. sakei $l d h L$ gene. Arrows represent the five ORFs and their orientation. The restriction sites are shown for Banll (B), EcoRI (E), Hincll (Hi), HindIII (H), Hpal (Hp), Sall (Sa) and Sspl (S). (b) Plasmid nomenclature and details of the inserts cloned in the different plasmids. pRV201-204, pRV207, pRV209 and pRV212 contain inserts cloned in pBluescript. pRV212 contains an insert cloned in the integrative vector pRV $300 . \mathrm{Cm}$, chloramphenicol-resistance gene of pC194.
HpaI-HindIII fragment from pRV201 was therefore subcloned in pBluescript $\mathrm{SK}+$ and used as a new probe to complete the restriction map at the $3^{\prime}$ end of the gene (Fig. 1a). A $2.3 \mathrm{~kb}$ EcoRI fragment adjacent to the insert cloned in pRV202 and pRV203 was detected and subsequently cloned, leading to pRV204 (Fig. 1b).

\section{DNA sequence of the $I d h L$ region}

The DNA sequence of the $6984 \mathrm{bp}$ cloned in the three overlapping DNA fragments was determined. Five ORFs were found, as shown in Fig. 1(a). The $5^{\prime}$ end of the first ORF, ORFA, extends from position 3136 to the EcoRI site at the end of the insert. The $1045 \mathrm{~N}$-terminal amino acids of the putative protein OrfA are $55.9 \%$ identical to the $\mathrm{N}$-terminal sequence of the protein encoded by the $m f d$ (mutation frequency decline) gene of Bacillus subtilis (Ogasawara et al., 1994). At 260 nucleotides upstream from ORFA a second ORF was found, extending from position 3930 to 3401 . The putative protein OrfB is $50.3 \%$ identical to the product of the spoVC gene of $B$. subtilis probably encoding a peptidyl tRNA hydrolase (Ogasawara et al., 1994). In B. subtilis, $m f d$ and spoVC are separated by a short putative gene, $y a b K$, that was not found between the two corresponding genes of L. sakei. The third ORF, in the opposite orientation to ORFA and ORFB, is the $l d h L$ gene, extending from positions 4161 to 5138 . The encoded L-LDH is $89 \%$ identical to the L. casei $\mathrm{L}-\mathrm{LDH}$ and shows the characteristic amino acids of the catalytic site. Only three differences were observed with the $l d h L$ sequence of the L. sakei 0-1 strain that has been sequenced by Van den Berg (1996). Two of these differences are immediately upstream of the start codon; the third is in the coding sequence but has no effect on the protein sequence. $l d h L$ probably starts at the TTG triplet at position 4161, since no other start codon is present in the $5^{\prime}$ end of the gene. Furthermore the homology with the L. casei L-LDH (Kim et al., 1991) extends to the amino acid sequence translated from the TTG triplet, upstream from which (at 10 nucleotides) there is a single GAAAGGA motif, resembling a ribosome-binding site. Twenty-four nucleotides downstream from the TAA stop codon of $l d h L$ (located at position 5136-5138), an imperfect palindromic sequence, able to form a stem-loop structure $\left(\Delta G^{0 \prime}\right.$ $-16.6 \mathrm{kcal} \mathrm{mol}^{-1} ;-69.4 \mathrm{~kJ} \mathrm{~mol}^{-1}$ ) was observed. This observation suggests that a transcription terminator is located downstream from $l d h L$. As indicated in Fig. $1(\mathrm{a})$, a short putative ORF, ORFC, in the opposite orientation to $l d h L$ was found, extending from position 5704 to 5216 . The $5^{\prime}$ end of ORFD was located 1156 nucleotides downstream from $l d h L$. No significant homology with any ORF in the databases could be found for ORFC and ORFD.

\section{Analysis of the transcription of $/ d h L$}

The transcription start site of $l d h L$ determined by primer extension on RNA prepared from glucose-grown bacteria was located at position 4122 on the sequence ( $39 \mathrm{bp}$ 
(a)

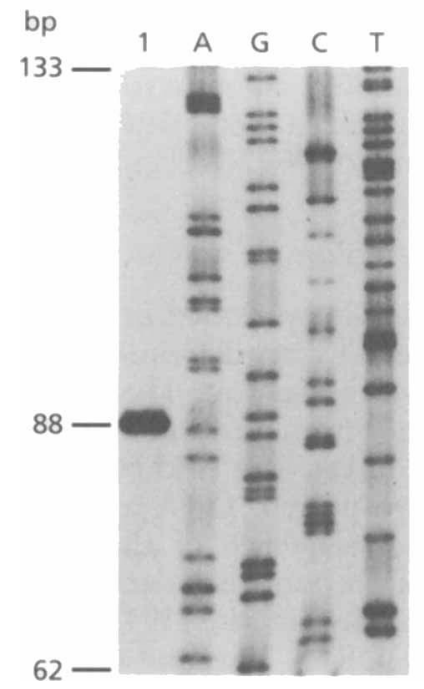

(b)

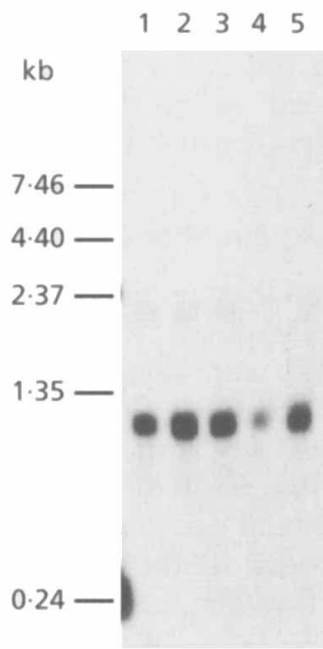

Fig. 2. Analysis of the transcription of $/ d h L$. (a) Primer extension experiment performed on total RNA extracted from L. sakei 207 (lane 1); the sequence obtained from M13mp19 with a universal primer was used as ladder (lanes A, C, G, T). (b) Northern blot on total RNAs extracted from $L$. sakei $23 \mathrm{~K}$ grown on MCD containing glucose (1), mannose (2), fructose (3), ribose (4) or glucose without thiamin (5). The probe used was a Hincll-Hincll fragment containing $l d h L$.

upstream from the translation initiation site of $l d h L$ ) (Fig. 2a). Two sequences resembling -10 and -35 boxes were observed at positions 4110 and 4084, respectively, on the sequence. Northern experiments were performed with RNA prepared from $L$. sakei $23 \mathrm{~K}$ grown in MCD in the presence of various carbohydrates, under microaerophilic conditions. The use of a HincllHincII probe encompassing $l d h L$ and ORFC revealed a transcript of $1.15 \mathrm{~kb}$ (Fig. $2 \mathrm{~b}$ ). No major variation in the signal intensity with the carbohydrate used as carbon source was observed. A second signal was observed that might have resulted from a cross-hybridization with the $\lambda$ DNA used for the molecular mass ladder, since this signal was not detected when $\lambda$ DNA was not used. A faint signal of approximately 700 nucleotides was detected after long exposure when a AflII-HindII probe corresponding to ORFC only was hybridized, suggesting that ORFC might indeed be expressed (data not shown). These data and the presence of a putative transcription termination signal at position 5162 suggest that $l d b L$ does not belong to a polycistronic operon but is rather transcribed as a small monocistronic transcript encoding only the L-LDH.

\section{Expression of the L. sakei IdhL gene in E. coli}

To demonstrate that the $l d b L$ gene cloned from the $L$. sakei chromosome does encode L-LDH, plasmids harbouring the gene were constructed in order to express it in E. coli. A plasmid carrying the coding part of $l d h L$ plus $165 \mathrm{bp}$ upstream from the start codon, including

the promoter, and $580 \mathrm{bp}$ downstream from the stop codon was constructed. For this purpose, the $715 \mathrm{bp}$ EcoRI-SalI fragment of pRV202 and the $1004 \mathrm{bp}$ EcoRI-HindII fragment of pRV204 were cloned at the SmaI and SalI sites of pBluescript SK +, leading to plasmid pRV207 (Fig. 1b). In pRV207, ldbL was in the opposite orientation to lacZ. The 1725 bp NotI-Sall insert of pRV207 was then cloned in the reverse orientation in pBluescript KS +, leading to pRV212 (see Fig. 1 b), in which the $l d h L$ gene is in the same orientation as lacZ and thus inducible by IPTG. E. coli TG1 transformants obtained with pRV212 as well as the control plasmid pBluescript SK + were grown on LB medium with or without IPTG induction. No significant amounts of lactate were detected in the culture supernatants. In crude extracts of the control strain, a basal LDH activity (1.5 \pm 0.5 units) was detected, that was not increased when FBP and $\mathrm{Mn}^{2+}$ were added. In the TG1 transformant obtained with pRV212, the same basal activity was observed. When FBP and $\mathrm{Mn}^{2+}$ were added, the LDH was strongly activated and activity reached $32 \pm 7 \cdot 4$ units. This activity was increased twofold after IPTG induction. These results demonstrate that the $l d h L$ gene does encode the $\mathrm{Mn}^{2+}$ - and FBP-activated LLDH of L. sakei.

\section{Construction of a stable mutant deficient in L-LDH}

Several enzymes might be responsible for D-lactate production, such as D-LDH or lactate racemase. Moreover, several enzymes or enzymic pathways might be responsible for L-lactate consumption, such as a lactate oxidase pathway, the lactate racemase or FAD-dependent LDHs. To estimate the role of racemase or other enzymes in lactate metabolism, we constructed an $l d h L$ mutant lacking an active L-LDH. For this purpose, the chloramphenicol-resistance gene of pC194 (Horinuchi \& Weisblum, 1982) was inserted at the EcoRI site of $l d h L$ in pRV207. The recombinant plasmid, pRV209, was obtained by the selection of chloramphenicolresistant $E$. coli transformants. Finally, the $l d b L$ gene containing the chloramphenicol cassette was cloned in the integrative vector $\mathrm{pRV} 300$. Two regions of approximately the same size (see Fig. 1b) flanked the chloramphenicol cassette. The recombinant plasmid, designated pRV211, was used to transform $L$. sakei $23 \mathrm{~K}$ to chloramphenicol resistance. A single-crossover recombination between pRV211 and the chromosomal $l d h L$ gene should lead to the integration of the total sequence of the plasmid, and thus should confer both chloramphenicol and erythromycin resistance. Two crossover events, between the chromosomal $l d h L$ gene and the upstream and downstream parts of the plasmid gene, surrounding the chloramphenicol resistance gene, should allow the integration of this resistance gene only. Among 542 transformants selected for their resistance to chloramphenicol, one appeared to be erythromycin sensitive after replica plating and might thus have integrated the mutated gene by double crossover. This recombinant clone was named RV2000. The structure of the mutated $l d h L$ gene in RV2000 was determined by 
(a)

(b)

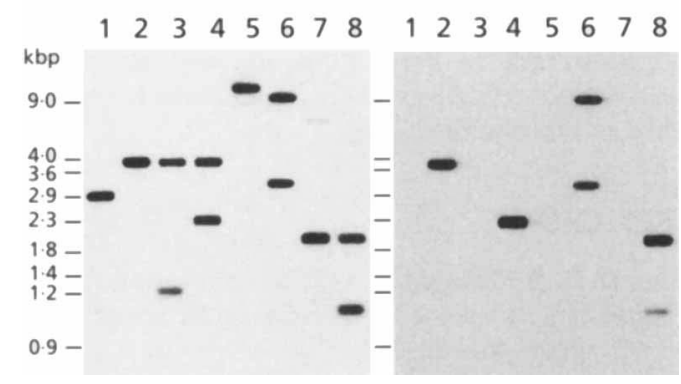

Fig. 3. Analysis of the structure of the $/ d h L$ gene in L. sakei $23 \mathrm{~K}$ and in the IdhL mutant RV2000. The IdhL gene (a) or the chloramphenicol-resistance gene (b) was used for Southern hybridization with chromosomal DNA extracted from 23K (lanes $1,3,5,7)$ or from RV2000 (lanes 2, 4, 6, 8). The restriction enzymes used were Banll (lanes 1, 2), Hpal (lanes 3, 4), Ncol (lanes 5, 6) and Sspl (lanes 7, 8).

Southern hybridization with various probes. No signal was observed when pRV300 was hybridized to DNA extracted from RV2000, showing that the recombinant plasmid had not been integrated by a single recombination event (data not shown). As shown in Fig. 3, when pRV207 or the chloramphenicol-resistance gene was used as probe the pattern observed with chromosomal DNA of $23 \mathrm{~K}$ and RV2000 was consistent with the chromosomal insertion in $l d h L$ of a $1 \mathrm{~kb}$ DNA fragment, the size of which corresponds to the chloramphenicolresistance gene.

The stability of the mutation in the chromosomal $l d b L$ gene was tested by growing the mutant strain on MRS medium without chloramphenicol, plating diluted aliquots of the culture on MRS, and then replica-plating on MRS plates containing chloramphenicol. After 100 generations, $100 \%$ of the clones were chloramphenicol resistant.

\section{Ability of the IdhL mutant to metabolize lactate}

The presence of L-lactate was measured in culture supernatants of RV2000 and the parent 23K (Fig. 4). After $72 \mathrm{~h}$ growth in MCD medium, the lactate concentration produced by $23 \mathrm{~K}$ was identical when bacteria were grown under aerobiosis or under microaerophily. The production of L-lactate was severely affected in RV2000, since only residual amounts were detected. The growth of RV2000 was also impaired as compared with $23 \mathrm{~K}$. The $\mathrm{pH}$ of the culture supernatants of L. sakei $23 \mathrm{~K}$ dropped from 6.5 at time zero to 3.6 after $72 \mathrm{~h}$ culture. In the supernatants of RV2000 mutant cultures, the $\mathrm{pH}$ dropped only to $6 \cdot 3$. Under aerobiosis, all glucose was utilized by R V2000 after 72 h growth, whereas the wildtype parent consumed only one-tenth of the glucose present in the medium. Under microaerophily, both strains utilized half of the glucose of the medium. The presence of acetoin and ethanol was detected after

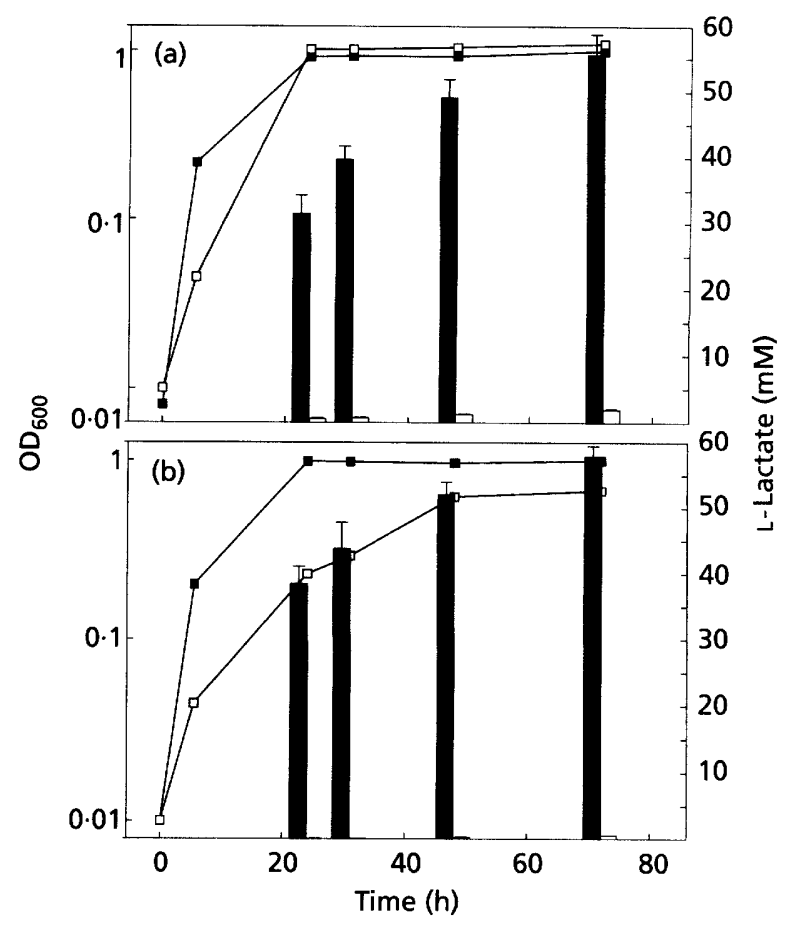

Fig. 4. Growth curves and amounts of L-lactate (bars) in culture supernatants of strains $23 \mathrm{~K}$ (filled symbols and bars) and RV2000 (open symbols and bars). Cells were grown in MCD medium containing $1 \%$ glucose. The cultures were aerated by vigorous shaking (a) or maintained under microaerophily (b).

growth of RV2000 whereas $23 \mathrm{~K}$ did not produce ethanol and produced only traces of acetoin.

The production of $\mathrm{D}$-lactate was determined in the wildtype and mutant strains. In MCD medium, D-lactate production was very low $(2-3 \mathrm{mM})$ in the parent strain. It has been reported that lactate racemase is inhibited by acetate (Stetter \& Kandler, 1973; Sneath et al., 1986), and MCD medium contains acetate. Since $L$. sakei grows poorly on MCD medium without acetate, MRS medium without acetate was used for subsequent experiments. In this medium, after $72 \mathrm{~h}$ aerobic cultivation with $1 \%$ glucose, the amount of D-lactate reached $32.58 \pm 4.05 \mathrm{mM}$ in $L$. sakei $23 \mathrm{~K}$, whereas RV2000 produced only $1 \cdot 0 \pm 0 \cdot 28 \mathrm{mM}$. The complex MRS medium contains L-lactate (approx. 8-10 mM). Surprisingly, in the culture supernatants obtained during aerobic growth of RV2000, only residual amounts of Llactate were found $(0 \cdot 70 \pm 0.24 \mathrm{mM})$, suggesting that the mutant strain is still able to degrade L-lactate. When $20 \mathrm{mM}$ or $50 \mathrm{mM}$ L-lactate was added to MRS, the consumption of lactate by RV2000 did not increase. LLactate consumption was not observed when RV2000 was grown under microaerophilic conditions. Under aerobiosis, the wild-type strain produced $9 \cdot 3 \pm 0 \cdot 1 \mathrm{mM}$ acetate, whereas the mutant strain produced $17 \cdot 22 \pm$ $2.78 \mathrm{mM}$ acetate, suggesting that the L-lactate utilization by RV2000 was not linked to its racemization but rather 
that L-lactate was then used through an oxygendependent pathway leading to acetate synthesis.

\section{Conclusions}

The results presented above show that the $l d b L$ gene encodes the L-LDH of $L$. sakei responsible for the production of L-lactate. $l d h L$ is transcribed as a monocistronic gene, as was described for Lactobacillus helveticus (Savijoki \& Palva, 1997), Pediococcus acidilactici (Garmyn et al., 1995) and L. plantarum (Ferain et al., 1994), and does not belong to a polycistronic operon, as was observed in Lactococcus lactis (Llanos et al., 1992). A mutant of $l d h L$ was constructed by integration into the chromosome by a double-crossover recombination. Although the construction of chromosomal mutations by recombination was recently described in L. sakei (Leloup et al., 1997; Stentz et al., 1997), this is, to our knowledge, the first report of the construction of a mutant in this species, by the direct selection for chromosomal integration by double crossover. The drastic decrease of $\mathrm{L}-$ and $\mathrm{D}$-lactate production caused by the mutation demonstrates that the L-LDH and the racemase are the two enzymes mainly responsible for the production of L- and D-lactate, respectively. The residual amounts of lactate found in the mutant strain might be due to a slight LDH activity of HicDHs due to their low affinity for pyruvate. The involvement of other types of LDHs, poorly expressed or poorly active, might also result in the residual production of lactate found in the mutant strain. The $l d h L$ mutant RV2000 was still able to degrade L-lactate, and no concomitant D-lactate production was observed. Other enzymes than racemase have been reported that are responsible for lactate consumption. Murphy et al. (1985) described an oxygendependent lactate-utilization pathway in $L$. plantarum that led to the production of acetate. Since L-lactate degradation in RV2000 was observed only aerobically, and since the amount of acetate that was produced by the mutant was twice as high as the amount observed in the wild-type strain, a similar pathway is suspected to be responsible for lactate utilization. However, a FADdependent LDH might also be responsible for the Llactate consumption, by catalysing its conversion to pyruvate. The racemase was not active in these conditions since no D-lactate was produced concomitantly with L-lactate consumption. It was previously shown that racemase is induced by L-lactate (Stetter \& Kandler, 1973). It is possible that the amount of intracellular lactate was too low to allow its induction or activation in these conditions. Although the growth of the mutant strain RV2000 was impaired, the deletion of the $l d h L$ gene was not lethal as was described in a thermosensitive ldhL mutant of Streptococcus mutans (Chen et al., 1994), possibly because of a shift from pyruvate to the production of end-products other than lactate, such as ethanol, acetoin and acetate. It was previously observed in L. plantarum by Ferain et al. (1994) that an $l d h L$ mutation had no effect on total lactate production, suggesting that $l d h L$ mutants can adapt the modified metabolic flux when a catabolic enzyme is inactive.

\section{ACKNOWLEDGEMENTS}

We are grateful to Costa Anagnostopoulos for critical reading of the manuscript, to Petar Pujic for his help with primer extension experiments and to Valérie Davant for her technical assistance in DNA sequencing.

\section{REFERENCES}

Anderson, D. G. \& McKay, L. L. (1983). Simple and rapid method for isolating large plasmid DNA from lactic streptococci. Appl Environ Microbiol 46, 253-261.

Barrit, M. M. (1936). The intensification of the Voges-Proskauer reaction by the addition of $\alpha$-naphthol. J Pathol Bacteriol 42, 441.

Bernard, N., Ferain, T., Garmyn, D., Hols, P. \& Delcour, J. (1991). Cloning of the D-lactate dehydrogenase gene from Lactobacillus delbrueckii subsp. bulgaricus by complementation in Escherichia coli. FEBS Lett 290, 61-64.

Bernard, N., Johnsen, K., Ferain, T., Garmyn, D., Hols, P., Holbrook, J. \& Delcour, J. (1994). NAD ${ }^{+}$-dependent D-2-hydroxyisocaproate dehydrogenase of Lactobacillus delbrueckii subsp. bulgaricus. Eur J Biochem 224, 439-446.

Berthier, F., Zagorec, M., Champomier-Vergès, M., Ehrlich, S. D. \& Morel-Deville, F. (1996). Efficient transformation of Lactobacillus sake by electroporation. Microbiology 142, 1273-1279.

Chen, A., Hillman, J. D. \& Duncan, M. (1994). L- $(+)$-Lactate dehydrogenase deficiency is lethal in Streptococcus mutans. J Bacteriol 176, 1542-1545.

De Man, J. C., Rogosa, M. \& Sharpe, M. E. (1960). A medium for the cultivation of lactobacilli. J Appl Bacteriol 23, 130-135.

Delcour, J., Bernard, N., Garmyn, D., Ferain, T. \& Hols, P. (1993). Génétique moléculaire des lactate-déshydrogénases des bactéries lactiques. Lait 73, 127-131.

Dower, W. J., Miller, J. F. \& Ragsdale, C. W. (1988). High efficiency transformation of $E$. coli by high voltage electroporation. Nucleic Acids Res 16, 6127-6145.

Ferain, T., Garmyn, D., Bernard, N., Hols, P. \& Delcour, J. (1994). Lactobacillus plantarum ldhL gene: overexpression and deletion. J Bacteriol 176, 596-601.

Ferain, T., Hobbs, J. N., Jr, Richardson, J., Bernard, N., Garmyn, D., Hols, P., Allen, N. E. \& Delcour, J. (1996). Knockout of the two ldh genes has a major impact on peptidoglycan precursor synthesis in Lactobacillus plantarum. J Bacteriol 178, 5431-5437.

Garmyn, D., Ferain, T., Bernard, N., Hols, P. \& Delcour, J. (1995). Cloning, nucleotide sequence, and transcriptional analysis of the Pediococcus acidilactici L-(+)-lactate dehydrogenase gene. Appl Environ Microbiol 61, 266-272.

Gibson, T. J. (1984). Studies on the Epstein-Barr virus genome. $\mathrm{PhD}$ thesis, Cambridge University, UK.

Hensel, R., Mayr, U., Stetter, K. O. \& Kandler, O. (1977). Comparative studies of lactic acid dehydrogenases in lactic acid bacteria. Arch Microbiol 112, 81-93.

Hillier, A. J. \& Jago, G. R. (1982). L-Lactate dehydrogenase, FDPactivated, from Streptococcus cremoris. Methods Enzymol 89, 362-367.

Hiyama, T., Fukui \& Kitahara, K. (1968). Purification and properties of lactate racemase from Lactobacillus sake.J Biochem 64, 99-107.

Horinuchi, S. \& Weisblum, B. (1982). Nucleotide sequence and functional map of pC194, a plasmid that specifies inducible chloramphenicol resistance. J Bacteriol 150, 815-825.

Hummel, W., Schütte, H. \& Kula, M. R. (1988). D-(-)-Mandelic 
acid dehydrogenase from Lactobacillus curvatus. Appl Microbiol Biotechnol 28, 433-439.

Kim, S. F., Baek, S. J. \& Pack, M. Y. (1991). Cloning and nucleotide sequence of the Lactobacillus casei lactate dehydrogenase gene. Appl Environ Microbiol 57, 2413-2417.

Lauret, R., Morel-Deville, F., Berthier, F., Champomier-Vergès, M., Postma, P. W., Ehrlich, S. D. \& Zagorec, M. (1996). Carbohydrate utilization in Lactobacillus sake. Appl Environ Microbiol 62, 1922-1927.

Leloup, L., Ehrlich, S. D., Zagorec, M. \& Morel-Deville, F. (1997). Single-cross-over integration in the Lactobacillus sake chromosome and insertional inactivation of the ptsI and lacL genes. Appl Environ Microbiol 63, 2117-2123.

Lerch, H. P., Blöcker, H., Kallwass, H., Hoppe, J., Tsai, H. \& Collins, J. (1989). Cloning, sequencing and expression in Escherichia coli of the D-2-hydroxyisocaproate dehydrogenase gene of Lactobacillus casei. Gene 78, 47-57.

Llanos, R., Hillier, A. \& Davidson, B. (1992). Cloning, nucleotide sequence, expression, and chromosomal location of $l d h$, the gene encoding $\mathrm{L}-(+)$-lactate dehydrogenase, from Lactococcus lactis. J Bacteriol 174, 6956-6964.

Murphy, M. G., O'Connor, L., Walsh, D. \& Condon, S. (1985). Oxygen dependent lactate utilization by Lactobacillus plantarum. Arch Microbiol 141, 75-79.

Ogasawara, N., Nakai, S. \& Yoshikawa, H. (1994). Systematic sequencing of the 180 kilobase region of the Bacillus subtilis chromosome containing the replication origin. DNA Res 1, 1-14.

Sambrook, J., Fritsch, E. F. \& Maniatis, T. (1989). Molecular Cloning: a Laboratory Manual, 2nd edn. Cold Spring Harbor, NY: Cold Spring Harbor Laboratory.
Savijoki, K. \& Palva, A. (1997). Molecular genetic characterization of the L-lactate dehydrogenase gene $(l d h L)$ of Lactobacillus belveticus and biochemical characterization of the enzyme. Appl Environ Microbiol 63, 2850-2856.

Sneath, P. H., Mair, N. S., Sharpe, M. E. \& Holt J. G. (editors) (1986). Bergey's Manual of Systematic Bacteriology, vol. 2. Baltimore: Williams \& Wilkins.

Stentz, R., Lauret, R., Ehrlich, S. D., Morel-Deville, F. \& Zagorec, M. (1997). Molecular cloning and analysis of the $p t s H I$ operon in Lactobacillus sake. Appl Environ Microbiol 63, 2111-2116.

Stetter, K. O. \& Kandler, O. (1973). Untersuchungen zur Entschlung von DL-Milchsäure bei Lactobacillen und Charakterisierung einer Milchsäureracemase bei einigen Arten der Untergattung Streptobacterium. Arch Mikrobiol 94, 221-247.

Tarmy, E. M. \& Kaplan, N. O. (1965). Interacting binding sites of Lspecific lactate dehydrogenase of Escherichia coli. Biochem Biophys Res Commun 21, 379-383.

Trüper, H. G. \& De Clari, L. (1997). Taxonomic note: necessary correction of specific epithets formed as substantives (nouns) 'in apposition'. Int J Syst Bacteriol 47, 908-909.

Van den Berg, D. (1996). A study to the production of exopolysaccharide by Lactobacillus sake $0-1$. PhD thesis, Utrecht University, The Netherlands.

Williams, J. G. \& Mason, P. J. (1985). Hybridization in the analysis of RNA. In Nucleic Acid Hybridization: a Practical Approach, pp. 139-160. B. D. Hames \& S. J. Higgins. Oxford: IRL Press.

Received 18 May 1998; revised 5 August 1998; accepted 2 September 1998. 